\title{
ESTRUTURA INSTITUCIONAL DO SETOR DE ENERGIA ELÉTRICA NO BRASIL E O DESENVOLVIMENTO SUSTENTÁVEL
}

\author{
INSTITUTIONAL STRUCTURE OF THE ELECTRICAL SECTOR IN BRAZIL AND SUSTAINABLE \\ DEVELOPMENT
}

\section{ESTRUCTURA INSTITUCIONAL DEL SECTOR ELÉCTRICO EN BRASIL Y DESARROLLO SOSTENIBLE}

Fabricio Quadros Borges ${ }^{1}$

\author{
Submetido em: 30/03/2021 \\ Aprovado em: 23/04/2021
}

\section{RESUMO}

O objetivo deste artigo é analisar, no campo teórico, as relações entre sustentabilidade energética e a Teoria da regulação de maneira a contribuir ao aperfeiçoamento do processo decisório no setor elétrico Brasileiro. As instituições do setor elétrico brasileiro enfrentam grandes desafios de mercado que pressionam estas organizações para que sejam capazes de planejar constantemente ações integradas e sustentáveis. Estes desafios estão vinculados ao atendimento premente por eletricidade e a necessidade de operar mecanismos eficientes para lidar com as questões ambientais. A metodologia, de natureza teórica, baseou-se em um levantamento bibliográfico relacionado aos temas: sustentabilidade energética, Teoria da regulação e indicadores de sustentabilidade. O estudo concluiu que apenas por meio da construção de um modelo de indicadores de sustentabilidade haverá orientação estratégica ao processo decisório em instituições reguladoras de eletricidade.

PALAVRAS-CHAVE: Sustentabilidade. Teoria da Regulação. Indicadores.

\begin{abstract}
The objective of this article is to analyze, in the theoretical field, the relationship between energy sustainability and the Theory of regulation in order to contribute to the improvement of the decisionmaking process in the Brazilian electric sector. Institutions in the Brazilian electricity sector face major market challenges that put pressure on these organizations to be able to constantly plan integrated and sustainable actions. These challenges are linked to the pressing need for electricity and the need to operate efficient mechanisms to deal with environmental issues. The methodology, of a theoretical nature, was based on a bibliographic survey related to the themes: energy sustainability, Regulation theory and sustainability indicators. The study concluded that only through the construction of a model of sustainability indicators will there be strategic orientation to the decision-making process in electricity regulatory institutions.
\end{abstract}

KEYWORDS: Sustainability. Regulation Theory. Indicators.

\section{RESUMEN}

El objetivo de este artículo es analizar, en el campo teórico, las relaciones entre la sostenibilidad energética y la Teoría de la regulación para contribuir a la mejora de la toma de decisiones en el sector eléctrico brasileño. Las instituciones del sector eléctrico brasileño enfrentan importantes desafíos de mercado que presionan a estas organizaciones para que puedan planificar constantemente acciones integradas y sostenibles. Estos desafíos están relacionados con la urgente necesidad de electricidad y la necesidad de operar mecanismos eficientes para hacer frente a los problemas ambientales. La metodología, de carácter teórico, se basó en una encuesta bibliográfica relacionada con los temas: sostenibilidad energética, teoría de la regulación e indicadores de

1 Pós-Doutor em Gestão de Tecnologia pelo IPEN/USP - Professor do Quadro Permanente do Instituto Federal do Pará - IFPA - https://orcid.org/0000-0002-1326-959X 


\section{RECIMA21 - REVISTA CIENTÍFICA MULTIDISCIPLINAR}

ESTRUTURA INSTITUCIONAL DO SETOR DE ENERGIA ELÉTRICA NO BRASIL E O DESENVOLVIMENTO SUSTENTÁVEL

sostenibilidad. El estudio concluyó que solo a través de la construcción de un modelo de indicadores de sustentabilidad habrá una orientación estratégica al proceso de toma de decisiones en las instituciones reguladoras de la electricidad.

PALABRAS CLAVE: Sostenibilidad. Teoría de la regulación. Indicadores.

\section{INTRODUÇÃO}

A promoção da sustentabilidade por meio do ambiente institucional tem sido um dos principais desafios no setor elétrico brasileiro, sobretudo a partir do processo de privatização do setor elétrico no país, onde a Agência Nacional de Energia Elétrica - Aneel, enquanto agência reguladora do setor, passou a desenvolver esforços em direção a busca de eficiência econômica e à proteção dos usuários do insumo energético diante de possíveis abusos de poder no monopólio. A busca da eficiência econômica se daria de forma a garantir o serviço de menor custo para o usuário e a busca da proteção aos usuários da energia elétrica, garantindo a menor diferença entre preço e custo deste insumo.

A energia elétrica compreende uma condição elementar ao processo de desenvolvimento de qualquer país na medida em que se constitui como um vetor estratégico, ao lado da água e saneamento, telecomunicações e transportes. A eletricidade por meio de suas peculiaridades físicoquímicas e eletromagnéticas da matéria possibilita o funcionamento de maquinários por intermédio de correntes de deslocamento de cargas elétricas dentro de um condutor (BORGES; RODRIGUES; OLIVEIRA, 2017).

A preocupação com a sustentabilidade energética no mundo cresce gradualmente, influenciada pela necessidade de garantir a segurança do aprovisionamento e fornecimento de energia bem como diminuir o aumento das temperaturas globais, associadas ao uso de combustíveis fósseis (ABBASI; TAUSEEF; ABBASI, 2011; OWUSU; ASUMADU-SARKODIE, 2016). O perfil das fontes de geração de energia elétrica possui relação com o padrão de vida das populações atendidas por esta eletricidade. É neste sentido que a energia elétrica é interpretada como vetor estratégico de desenvolvimento de regiões e países, a partir de meandros econômicos, sociais e ambientais.

A energia elétrica fornecida para residências no Brasil compreende um aspecto que chama cada vez mais a atenção quando se discute o papel da energia elétrica para a melhoria da qualidade de vida dos brasileiros. Se de um lado o país conta dominantemente com uma fonte de geração de eletricidade com baixos custos relativos, as hidrelétricas, por outro os custos de energia elétrica no país são bastante altos em comparação com outros países (BORGES; RODRIGUES; OLIVEIRA, 2017).

Esta investigação está delimitada ao ambiente institucional da Aneel. A realidade de enfrentamento dos desafios de mercado no setor elétrico brasileiro, alicerçada no atendimento premente pelo insumo elétrico e nos mecanismos usados para tratar as questões socioambientais, pressiona substancialmente não apenas a Aneel, mas as instituições do setor para que estejam 


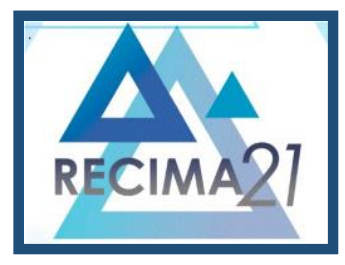

\section{RECIMA21 - REVISTA CIENTÍFICA MULTIDISCIPLINAR}

ESTRUTURA INSTITUCIONAL DO SETOR DE ENERGIA ELÉTRICA NO BRASIL E O DESENVOLVIMENTO SUSTENTÁVEL

organizadas e sejam capazes de planejar ações integradas e sustentáveis em todas as regiões do país (BORGES; BORGES, 2014).

Nesta perspectiva a problemática deste artigo está apoiada no seguinte problema de pesquisa: de que forma instituições de regulação de distribuição de eletricidade poderiam aperfeiçoar o processo de tomada de decisão? A contribuição deste questionamento visa a contribuição ao fomento e ao desenvolvimento de pesquisas relacionadas ao tema, de maneira a levantar, estrategicamente, subsídios ao processo decisório no setor elétrico brasileiro. A oportunidade de investigação traz uma perspectiva de evolução de indicadores de sustentabilidade no setor elétrico em favorecimento à melhoria da qualidade de vida da população brasileira; norteando as empresas do setor elétrico que queiram buscar um desenvolvimento sustentável para a diminuição dos impactos sociais e ambientais construindo assim, para uma matriz energética mais sustentável garantindo a sustentabilidade para a futuras gerações.

A preocupação das instituições com a mensuração da sustentabilidade energética, sobretudo quanto aos riscos envolvidos em suas operações (que podem ser riscos diretos, como passivos ambientais e ações legais, ou riscos indiretos, como comprometimento da imagem e consequente diminuição de vendas e do valor das ações), compreende um foco cada vez mais abordado internacionalmente (TÁRREGA; PEREZ, 2007). É crescente o interesse sobre a construção de indicadores de sustentabilidade na intenção de orientação de processos decisórios. As abordagens referentes a estratégias, produção mais limpa, controle da poluição, ecoeficiência, gestão ambiental, responsabilidade social, ecologia industrial, investimentos éticos, economia verde, eco design, reuso, consumo sustentável, resíduos zero, são cada vez mais frequentes (GLAVIC; LUKMAN, 2007).

O setor elétrico brasileiro, diante do alto consumo de energia elétrica, precisa garantir ao país segurança na produção e distribuição de eletricidade, assim como, padrões competitivos para este insumo. Este desafio precisa observar aspectos econômicos, sociais e ambientais que não prejudiquem as atuais e nem as futuras gerações; cabe a Aneel, a missão de proporcionar condições favoráveis para que o mercado de energia elétrica se desenvolva com equilíbrio entre os agentes e em benefício da sociedade brasileira.

O objetivo deste artigo é analisar, no campo teórico, as relações entre sustentabilidade energética e a Teoria da regulação de maneira a contribuir ao aperfeiçoamento do processo decisório no setor elétrico Brasileiro. Esta proposta de pesquisa se justifica pela oportunidade de levantar subsídios ao processo de tomada de decisão na Aneel. A tentativa é de orientar, por meio da elaboração de uma modelo de indicadores de sustentabilidade energética, uma gestão de distribuição de energia elétrica a partir de bases sustentáveis.

A análise do papel do setor elétrico no desenvolvimento socioeconômico brasileiro representa ainda uma oportunidade de diálogo da contraposição de ideias alicerçadas pela tensão de opostos e por profundas contradições. Este processo dialético atribui uma maior complexidade ao debate energético e tem o propósito de revelar novas possibilidades de compreensão das relações 


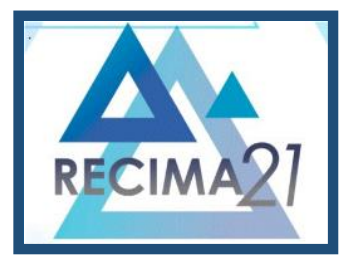

\section{RECIMA21 - REVISTA CIENTÍFICA MULTIDISCIPLINAR}

ESTRUTURA INSTITUCIONAL DO SETOR DE ENERGIA ELÉTRICA NO BRASIL E O DESENVOLVIMENTO SUSTENTÁVEL

entre energia elétrica e desenvolvimento da sociedade como um todo. No decorrer desta tese verificam-se estas contradições econômicas, sociais e política, que compõe um mesmo panorama.

$\mathrm{Na}$ realidade, a presente análise procura subsidiar ações futuras para a utilização do potencial elétrico paraense em direção à prática do desenvolvimento socioeconômico. Assim, todo este esforço está pautado em uma concepção cuja experiência adquirida com o passado, alimentadas por observações presentes, cria condições de melhor orientar o planejamento público. Entretanto, a coleta de ensinamentos e diretrizes nem sempre compreende uma tarefa de simples consulta ao passado apenas para colher críticas ao presente, desprezando as incertezas e armadilhas do tempo, sem maiores compromissos com a construção do futuro (REIS; FADIGAS; CARVALHO, 2012).

O universo das reflexões deve ser baseado na percepção de que o futuro é alicerçado por ações verificadas a cada momento, mas sua realização estará sujeita a variadas forças que estão além do alcance dos estudiosos e que até mesmo surgem de forma completamente imprevista (REIS; FADIGAS; CARVALHO, 2012). O texto, além desta introdução é dividido didaticamente em cinco partes a saber: aspectos metodológicos, estrutura institucional brasileira do setor de energia elétrica, concepção do referencial normativo do desenvolvimento sustentável, análise do ambiente regulatório e a sustentabilidade, e as considerações finais.

\section{ASPECTOS METODOLÓGICOS}

A investigação compreende um esforço de natureza teórica e, conforme a taxionomia de Vergara (2016), pode ser classificado quanto aos seus fins e quanto aos seus meios. Quanto aos fins é considerado com o exploratório, na medida em que envolve um levantamento de subsídios nos meandros do ambiente da estrutura institucional do setor elétrico brasileiro e do referencial normativo do desenvolvimento sustentável. E quanto aos seus meios, é apoiado em um levantamento bibliográfico e documental, na medida em que se utiliza de um levantamento de materiais e documentos junto a órgãos vinculados ao setor energético do país.

A metodologia foi didaticamente dividida em três etapas: coleta de dados, tratamento de dados e análise de dados. A coleta de dados se utilizou de livros, artigos científicos e documentos, que foram levantados entre 17 de janeiro e 18 de março de 2020. As categorias focais foram: setor elétrico brasileiro, desenvolvimento sustentável, sustentabilidade energética e Teoria da regulação. 0 tratamento de dados procurou organizar o material coletado na intenção de produzir informações em condições razoáveis de análise. Por fim, a análise de dados realizou-se de maneira a examinar as relações entre as categorias focais mencionadas, de maneira a levantar subsidios ao processo de tomada de decisão no setor elétrico brasileiro. 


\section{RECIMA21 - REVISTA CIENTÍFICA MULTIDISCIPLINAR}

ESTRUTURA INSTITUCIONAL DO SETOR DE ENERGIA ELÉTRICA NO BRASIL E O DESENVOLVIMENTO SUSTENTÁVEL

\section{ESTRUTURA INSTITUCIONAL BRASILEIRA DO SETOR DE ENERGIA ELÉTRICA}

A análise da organização institucional do setor elétrico será aqui alicerçada a partir da menção a três definições indispensáveis à compreensão dos meandros que se apresentam no cenário desta temática: a energia elétrica, o setor energético e o setor elétrico. A energia elétrica compreende 0 produto de um processo adequado de uso de propriedades físico-químicas e eletromagnéticas da matéria para propiciar o funcionamento de equipamentos fornecedores de usos finais pela sociedade (REIS; FADIGAS; CARVALHO, 2012). Neste sentido, a energia elétrica é considerada um insumo de natureza secundária, já que é oriunda da ação primária de conversores. As conversões de energia primária em elétrica mais utilizadas atualmente são de: energia térmica, que é aquela encontrada nos combustíveis fósseis e na biomassa através das usinas termelétricas; energia atômica de minerais radioativos a partir de usinas nucleares; e potencial hídrico através das usinas hidrelétricas (CAMARGO; UGAYA; AGUDELO, 2004).

O setor energético, por sua vez, compreende um conjunto de órgãos que procuram promover a utilização estratégica de diferentes fontes de energia a partir de recursos energéticos, econômicos e tecnológicos disponíveis. Neste sentido, constitui-se de um sistema aberto que estabelece relações entre seus subsistemas: elétrico, carvão, petróleo, gás e outros. Apesar deste trabalho não discutir amplamente a abordagem sistêmica, faz-se necessário destacar que o termo "sistema" no ambiente energético engloba características ecológicas, tecnológicas, sociais, econômicas e institucionais, assim como os segmentos da cadeia produtiva da energia.

A estrutura institucional do setor de energia elétrica compreende um sistema composto por organizações e suas respectivas conexões, que possuem o propósito de alimentar um processo de transformação da energia considerada primária em um insumo pronto para consumo final. Este sistema é composto basicamente por três elementos: geração de energia, transmissão de energia e distribuição de energia.

A geração de energia elétrica compreende todo o processo de transformação de uma fonte primária de energia em eletricidade e representa uma parte bastante significativa dos impactos ambientais, socioeconômicos e culturais dos sistemas de energia elétrica (REIS; FADIGAS; CARVALHO, 2012).

A eletricidade produzida nas centrais de geração percorre normalmente um longo caminho até o seu local de uso. Este percurso envolve os sistemas de transmissão, que interligam a geração aos centros de carga (nos casos onde a distribuição não se conecta diretamente à transmissão utilizamse os sistemas de subtransmissão). Por fim, o componente distribuição de energia elétrica constituise basicamente como a eletricidade entregue aos consumidores deste insumo, que por sua vez, se encontram ligados rede elétrica.

Quanto às relações do setor elétrico com a sociedade, salienta-se, inclusive, a necessidade de que se assegure o direito à informações e documentos sobre a construção de barragens desde as 


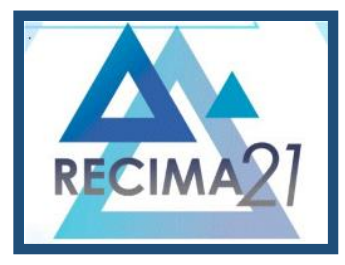

\section{RECIMA21 - REVISTA CIENTÍFICA MULTIDISCIPLINAR}

ESTRUTURA INSTITUCIONAL DO SETOR DE ENERGIA ELÉTRICA NO BRASIL E O DESENVOLVIMENTO SUSTENTÁVEL

sondagens preliminares encaminhadas à Aneel (CAMARGO; UGAYA; AGUDELO, 2004). A demanda de eletricidade no Brasil tende a crescer rapidamente no futuro previsível e a reforma do setor elétrico deve centrar-se no investimento. Mais ainda, o grande sistema hidrelétrico do Brasil precisa de tratamento especial para se ter investimentos em plantas hidráulicas e térmicas. Se reconhecermos esses fatos deve-se: declarar moratória sobre privatização de geradoras pelos próximos seis a sete anos; trabalhar seriamente durante o período para definir um conjunto de regras transparentes, abrangentes e politicamente viáveis para administrar conflitos pelo uso de reservatórios; e substituir os atuais arranjos comerciais, de preço garantido casuístico, não regulado e disfarçado sob retórica de competição. Neste contexto, o Governo Federal precisava estruturar um modelo para o setor elétrico que garantisse 0 aumento da oferta a contento do crescimento econômico brasileiro.

Em 2003, o Brasil começava a observar o surgimento de um modelo novo para a estrutura institucional de energia elétrica. Conforme a Lei 10.848/2004, a nova estrutura procura implementar políticas públicas voltadas para a cadeia de eletricidade. Nesta perspectiva, a garantia de suprimento de energia elétrica e as tarifas praticadas seriam objeto de atenção do setor elétrico (BORGES; CHOTOE, 2013). De acordo com o novo modelo, o setor elétrico brasileiro, para a realização de seus propósitos, passa a fazer uso de funções estratégicas que procuram desenvolver suas ações, através de uma estrutura institucional integrada. A formulação de políticas e diretrizes do setor elétrico é desenvolvida a partir: do Congresso Nacional, da Câmara de Políticas de Infraestrutura do Conselho de Governo e a partir do Conselho Nacional de Política Energética (CNPE). A orientação das políticas e das diretrizes do setor elétrico conforme o interesse da sociedade representa alicerce fundamental a uma política energética sustentada.

O CNPE, na condição de órgão específico do setor elétrico brasileiro e submetido à aprovação da Presidência da República, deve ser observado com maior atenção. Conforme o Decreto №. 3.520, de 21 de junho de 2000, que dispõe sobre a estrutura e funcionamento do órgão, observa-se que o mesmo desenvolve políticas destinadas a: preservação do interesse nacional, promoção do desenvolvimento sustentado, proteção do meio ambiente e promoção da conservação de energia, atração de investimentos na produção de energia, revisão das matrizes energéticas, entre outras. Para a operacionalização destas políticas o órgão conta com o suporte de oito comitês técnicos: Consumidor e tarifas; Planejamento do suprimento de energia elétrica; Matriz energética; Eficiência energética; Atração de investimentos e marcos legais; Fontes renováveis complementares; Importação de energéticos e sistema nacional de estoque de combustíveis; e Meio ambiente. $O$ CNPE, conforme o Decreto 3.520/2000 é formado pelo: Ministro de Estado de Minas e Energia, que preside o órgão, Ministro de Estado da Ciência e Tecnologia, Ministro de Estado de Planejamento, Orçamento e Gestão; Ministro de Estado da Fazenda; Ministro de Estado do Meio Ambiente; Ministro de Estado do Desenvolvimento, Indústria e Comércio Exterior; Ministro de Estado da Casa Civil da Presidência da República; um representante dos Estados e do Distrito Federal; um cidadão brasileiro 


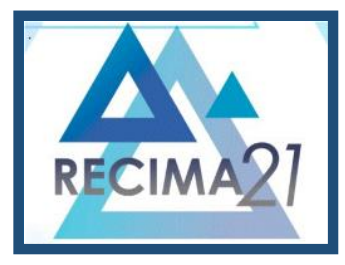

\section{RECIMA21 - REVISTA CIENTÍFICA MULTIDISCIPLINAR}

ESTRUTURA INSTITUCIONAL DO SETOR DE ENERGIA ELÉTRICA NO BRASIL E O DESENVOLVIMENTO SUSTENTÁVEL

especialista em matéria de energia; um representante de Universidade brasileira especialista em matéria de energia (BRASIL, 2000). O planejamento e a garantia do equilíbrio entre oferta e demanda, enquanto função estratégica do setor elétrico compreende a missão do Ministério de Minas e Energia (MME).

O MME desenvolve ações voltadas a uma maior participação do setor privado junto aos investimentos e à responsabilidade pela manutenção das reservas de energia do país através de um organograma linear (Figura 6). Sua estrutura possui duas empresas vinculadas na condição de sociedade de economia mista: a Eletrobrás e a Petrobrás. A Eletrobrás, que será objeto da atenção por estar voltada ao setor elétrico, dirige as empresas Furnas Centrais Elétricas S. A., Companhia Hidroelétrica do São Francisco (Chesf), Companhia de Geração Térmica de Energia Elétrica (CGTEE), Eletrosul Centrais Elétricas S.A. (Eletrosul), Eletrobrás Termonuclear S. A. (Eletronuclear) e Centrais Elétricas do Norte do Brasil S. A. (Eletronorte).

A regulação e a delegação do poder concedente compreendem outra função da estrutura institucional. Sua missão é a garantia do suprimento e da qualidade dos serviços de energia pública. A operacionalização desta missão se dá através da Aneel, que é uma autarquia em regime especial vinculada ao Ministério de Minas e Energia e que foi criada pela Lei ㄲo. 9.427 de 1996. O propósito da Aneel é o de: regular e fiscalizar a geração, a transmissão, a distribuição e a comercialização da energia elétrica; mediar os conflitos de interesses entre os agentes do setor elétrico e entre estes e os consumidores; conceder, permitir e autorizar instalações e serviços de energia; garantir tarifas justas; zelar pela qualidade do serviço; exigir investimentos; estimular a competição entre os operadores e assegurar a universalização dos serviços. A Aneel tem o desafio de definir com clareza os mecanismos que garantam a satisfação das necessidades da população por energia elétrica.

\section{CONCEPÇÃO DO REFERENCIAL NORMATIVO DO DESENVOLVIMENTO SUSTENTÁVEL}

O termo desenvolvimento, em qualquer concepção, deve resultar do crescimento econômico acompanhado de aperfeiçoamento no padrão de vida das populações, isto é, seria resultado de modificações na estrutura do produto e a alocação de recursos pelos diferentes setores da economia, de forma a melhorar os indicadores de bem-estar econômico e social (GARCíA, 2010). Nesta dinâmica de entendimento, García, (2010) aponta a existência de duas correntes de pensamento econômico sobre o tema. A primeira corrente encara o crescimento como sinônimo de desenvolvimento, enquanto na segunda crescimento é condição indispensável para o desenvolvimento, mas não é condição suficiente (GARCíA, 2010). Na primeira corrente estão os modelos de crescimento da tradição clássica e neoclássica; enquanto na segunda corrente, estão os economistas de orientação crítica, formados na tradição marxista ou cepalina, que conceitua o crescimento como uma simples variação quantitativa do produto, enquanto desenvolvimento é 


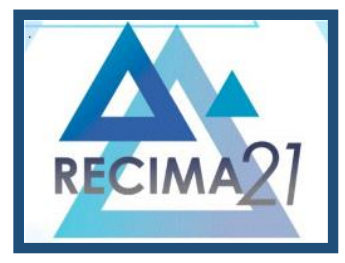

\section{RECIMA21 - REVISTA CIENTÍFICA MULTIDISCIPLINAR}

ESTRUTURA INSTITUCIONAL DO SETOR DE ENERGIA ELÉTRICA NO BRASIL E O DESENVOLVIMENTO SUSTENTÁVEL

caracterizado por mudanças qualitativas no modo de vida das pessoas, nas instituições e nas estruturas produtivas (FURTADO, 2007).

O desenvolvimento sustentável e a sustentabilidade são assuntos que permeiam o mundo no ambiente governamental e no ambiente organizacional. Em um cenário internacional constituído e preocupado com as questões climáticas, escassez de recursos naturais e a crise hídrica, o tema desperta para a reflexão em se trabalhar conjuntamente para a construção de uma sociedade mais sustentável. A relevância e abrangência deste ambiente de reflexão se dá pelas dimensões e pelas conexões que estão inseridas em um processo de desenvolvimento e das bases econômicas, sociais e ambientais para este desenvolvimento.

A definição do referencial normativo do desenvolvimento sustentável reside mergulhada em contradições, na medida em que a dificuldade reside no fato de que os interesses econômicos não são submissos aos interesses sociais e ambientais. As discussões a respeito do desenvolvimento de nações e o estágio de globalização, em maior parte, alterou o significado da categoria desenvolvimento sustentável no instante que questiona se este termo é usado apenas para o aprofundamento das conexões de poder do capital. A conceituação desta categoria sugestiona nova ordem internacional, que possui como propósito uma reordenação do poder e que não considera conexões de forças que são dominantes no mercado internacional, e os interesses dos países com indústrias mais desenvolvidas em garantir a colocação vantajosa no cenário internacional (BORGES; RODRIGUES; OLIVEIRA, 2017; GLAVIC; LUKMAN, 2007).

Nesta perspectiva, constata-se que a ideia mais aceitável para a construção do entendimento do desenvolvimento sustentável, de forma a iniciar uma contribuição ao termo a partir de uma dimensão mais categórica, alicerça-se na ideia de que o desenvolvimento sustentável compreende uma condição de crescimento contínuo de uma economia, de modo a permitir uma razoável distribuição concreta da riqueza social através da ampliação do acesso das populações à satisfação de necessidades básicas como saúde, educação, energia, água e saneamento (BORGES, 2015).

O desenvolvimento sustentável possui o objetivo de promover a sustentabilidade. Os percalços definição e transmissão da categoria sustentabilidade indica a dificuldade em traduzir os conceitos em ações corriqueira e permanentes (BORGES, 2015). O termo sustentabilidade é utilizado, mas pouco explicado. É de natureza conceitual, mal compreendido (MARZALL, 1999). Trata-se de um modismo ou um senso comum (MARZALL, 1999). A sustentabilidade vincula-se a uma atividade que pode ser mantida por um período de tempo indeterminado, de modo a não alcançar seu esgotamento, apesar dos imprevistos que podem ocorrer durante esse período, a partir de bases econômicas, sociais e ambientais relativamente consistentes (BORGES, 2009). A sustentabilidade seria então definida como a capacidade de sustentar condições econômicas, sociais e ambientais promotoras do atendimento das necessidades humanas de maneira equilibrada; nesta perspectiva, a possibilidade de avaliar a sustentabilidade junto a instituições está 


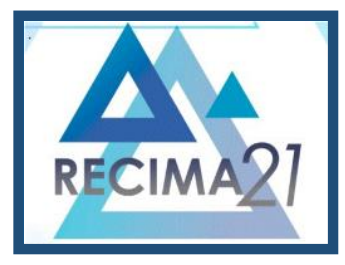

\section{RECIMA21 - REVISTA CIENTÍFICA MULTIDISCIPLINAR}

ESTRUTURA INSTITUCIONAL DO SETOR DE ENERGIA ELÉTRICA NO BRASIL E O DESENVOLVIMENTO SUSTENTÁVEL

condicionada a elaboração de instrumentos mensuradores, isto é, à construção de indicadores de sustentabilidade voltados à dimensão institucional (BORGES, 2015).

Os indicadores, termo originário do latim indicare que significa descobrir, apontar e estimar, podem comunicar ou informar sobre o progresso em direção a uma determinada meta, como por exemplo o desenvolvimento sustentável, mas também podem ser entendidos como um recurso que deixa mais perceptível uma tendência ou fenômeno, que não seja imediatamente detectável (HAMMOND et al., 1995). Assim, um indicador compreende um parâmetro, ou valor derivado de parâmetros, que aponta e fornece informações sobre o estado de um fenômeno com uma extensão significativa.

$\mathrm{Na}$ intenção de apurar o estado da arte dos indicadores, o World Resources Institute (WRI) realizou um estudo no início da década dos anos de 1990 para identificar o estágio de compreensão deste termo e de seus níveis de aplicação a partir das pesquisas que foram ou estavam sendo efetuadas até então (HAMMOND et al., 1995). Estas investigações examinaram programas elaborados por inúmeros organismos nacionais e internacionais, onde se verificou que o marco de referência dos indicadores de sustentabilidade foi a Conferência Mundial sobre meio ambiente e desenvolvimento, a Rio-92, com a construção de seu documento final, a Agenda 21 (MARZALL, 1999).

A discussão sobre indicadores de sustentabilidade energética está diretamente vinculada ao debate a respeito de metodologias para a medição do nível do desenvolvimento de sociedades e da sustentabilidade de seus sistemas de produção, que podem fornecer informações sobre um determinado fenômeno que é importante para o desenvolvimento e seriam demonstrados através destes indicadores (REIS; FADIGAS; CARVALHO, 2012). O uso de indicadores é extremamente importante no processo de aperfeiçoamento da sociedade e da economia como um todo, todavia, o número de indicadores de desenvolvimento sustentável disponíveis na literatura é excessivo e frequentemente demonstra a ausência de uma metodologia que integre as dimensões econômica, social e ambiental; os estudos sobre indicadores mais específicos possuem avanços relativamente mais restritos (REIS; FADIGAS; CARVALHO, 2012).

Nesse contexto, qualquer variável, e consequentemente qualquer indicador, seja ele descritivo ou normativo, tem uma significância particular. A mais importante característica do indicador, quando comparado com os outros tipos ou formas de informação, é a sua relevância para a política e para o processo decisório. Neste sentido, para ser representativo, o indicador tem que ser considerado importante tanto por quem toma decisões quanto pelo público. Os indicadores mais desejados são aqueles que resumam ou simplifiquem as informações relevantes, façam com que certos fenômenos que ocorrem na realidade se tornem mais aparentes; aspecto esse que é particularmente importante na gestão ambiental; nessa área, especificamente, é necessário que sejam quantificadas, mensuradas e comunicadas as ações relevantes. 


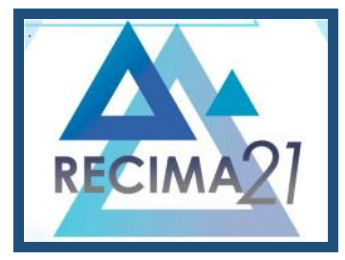

\section{RECIMA21 - REVISTA CIENTÍFICA MULTIDISCIPLINAR}

ESTRUTURA INSTITUCIONAL DO SETOR DE ENERGIA ELÉTRICA NO BRASIL E O DESENVOLVIMENTO SUSTENTÁVEL

No ambiente das organizações, a sustentabilidade possui caminhos desafiadores. A sustentabilidade é o equilíbrio entre os três pilares: ambiental, econômico e social. A expectativa de que as empresas devem contribuir de forma progressiva com a sustentabilidade surge do reconhecimento de que os negócios precisam de mercados estáveis, e que devem possuir habilidades tecnológicas, financeiras e de gerenciamento necessário para possibilitar a transição rumo ao desenvolvimento sustentável (VAN MARREWIJK; HARDJONO, 2003).

Alguns autores destacam a definição do conceito Triple Bottom Line (TBL) por Elkington em 1987, relacionando três pilares para analisar o fenômeno sustentabilidade a partir das perspectivas: econômica, social e ambiental (VAN MARREWIJK; HARDJONO, 2003).]. A formação de um triple bottom line pode ser refletida em termos de aumento no valor da empresa, que pode ser obtido por meio de ganhos em torno de seu capital social, humano e ambiental, que podem ser mensurados através de diversos elementos. A seguir, apresentam-se alguns modelos de indicadores de sustentabilidade energética disponíveis na literatura.

Os indicadores do IBGE (2020) são formados pelos aspectos econômico, social, ambiental e institucional. $O$ processo de construção destes instrumentos compõe o empenho mundial para operacionalizar as premissas estabelecidas na Agenda 21, da Conferência das Nações Unidas sobre Meio Ambiente e Desenvolvimento, no que tange as relações meio ambiente, desenvolvimento e aporte ao processo decisório (IBGE, 2020). Os indicadores da Aneel, por sua vez, são compostos de dimensões: econômicas; sociais; ecológicos; tecnológicos; e políticos. Este sistema de indicadores não aborda o ambiente institucional de maneira efetiva. Os aspectos políticos são os que mais se aproximam ao ambiente institucional. Os indicadores utilizados são apenas: a segurança no abastecimento e desconcentração de poder público, não atribuindo, portanto, representatividade e precisão na avaliação de instituições do setor elétrico (BORGES, 2015).

A proposta de Camargo, Ugaya e Agudelo (2004), também surge na literatura como uma indicação importante. Estes indicadores podem ser: sociais, econômicos e ambientais. Os indicadores econômicos são: despesas com salários e benefícios; impostos e taxas em geral; investimento em segurança, meio ambiente e saúde; investimento em pesquisa e desenvolvimento; investimento em desenvolvimento comunitário; investimento em tecnologia nacional; e patrocínio de projetos ambientais (CAMARGO; UGAYA; AGUDELO, 2004). Os indicadores sociais são: alimentação; encargos sociais; pagamentos à previdência particular; atendimento médico aos funcionários; quantidade de acidentes laborais; investimento em aprimoramento dos funcionários; quantidade de doenças ocupacionais; investimentos em projetos culturais aos funcionários; capacidade de desenvolvimento profissional; quantidade de trabalhadoras na organização; participação nos lucros; transparência e comunicação das informações; quantidade de funcionários portadores de deficiência; porcentagem de postos de trabalho de gestão ocupados por mulheres; eficácia das contribuições para a sociedade; ações judiciais relativas a problemas ambientais; empregados treinados ISO 14.004; investimentos em educação para a comunidade; investimentos 


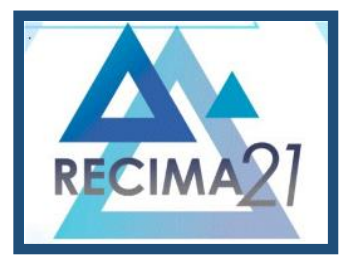

\section{RECIMA21 - REVISTA CIENTÍFICA MULTIDISCIPLINAR}

ESTRUTURA INSTITUCIONAL DO SETOR DE ENERGIA ELÉTRICA NO BRASIL E O DESENVOLVIMENTO SUSTENTÁVEL

em pesquisa universitária (CAMARGO; UGAYA; AGUDELO, 2004). Já os indicadores ambientais são: qualidade do ar; eficiência energética; utilização de recursos naturais; qualidade ambiental; qualidade da água; e preocupação com o meio ambiente (CAMARGO; UGAYA; AGUDELO, 2004).

Os indicadores podem atribuir ordens de grandeza ao estado de sustentabilidade do setor elétrico a partir de cada setor da economia, de forma a orientar o processo decisório. Os setores da economia apresentam diferentes demandas de eletricidade, potencial de geração de empregos, valores agregados, necessidades de investimentos, níveis de eficiência, entre outros elementos que atuam diante de características especificas.

\section{ANÁLISE DO AMBIENTE REGULATÓRIO E A SUSTENTABILIDADE}

Os setores de infraestrutura no Brasil sofreram uma reestruturação decorrente da substituição do Estado pela iniciativa privada na sua operação, o que resultou na necessidade de desenvolver novos marcos regulatórios (PIRES; PICCININI, 1999). A administração pública brasileira caminhou nas últimas décadas voltada para um debate que versava sobre o tamanho ideal do Estado, quando na realidade, o que se fazia premente era pensar este Estado a partir de bases efetivamente sustentáveis.

Nesta nova perspectiva, a regulação passou assumir uma missão de incentivar e garantir os investimentos necessários, promover o bem-estar dos usuários e elevar a eficiência econômica; compreendendo o ambiente que envolve o processo de produção de regras e de orientação das condutas dos atores em um determinado espaço social (PIRES; PICCININI, 1999). Dentre os grandes desafios da atividade regulatória, está a busca de equilíbrio no ambiente das relações entre os consumidores, o Estado e os agentes econômicos (GARCíA, 2010). Todavia, a democratização política, as privatizações relativamente recentes, o funcionamento das estruturas regulatórias e 0 nível de organização de instituições públicas no Brasil ainda não foram capazes de permitir a consolidação de uma rede eficiente de governança comprometida com o desenvolvimento sustentável (BORGES; BORGES, 2014).

No debate a respeito da reforma do Estado, um entrave comum é a confusão interpretativa entre regulação e regulamentação, pois tais expressões diferem, pois, regulação diz respeito ao ato de regular, e regulamentação refere-se a um conjunto de determinações executivas que complementa com minúcias uma lei, para executar seu cumprimento (BURSZTYN, 1998). Ao Estado, enquanto operador econômico, cabe a função de regular as relações entre os diversos agentes do sistema socioeconômico, podendo lançar mão de diferentes artifícios, tais como a regulamentação ou ação direta, visto que um artifício não exclui o outro, embora a utilização de ambos simultaneamente tenha agravado o poder estatal, gerando fragilidades nas instituições públicas (BURSZTYN, 1998). 


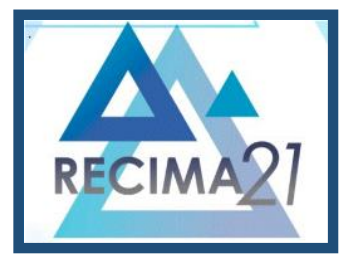

\section{RECIMA21 - REVISTA CIENTÍFICA MULTIDISCIPLINAR}

ESTRUTURA INSTITUCIONAL DO SETOR DE ENERGIA ELÉTRICA NO BRASIL E O DESENVOLVIMENTO SUSTENTÁVEL

A regulação compreende o ambiente que envolve o processo de produção de regras e de orientação das condutas dos atores em um determinado espaço social; os principais objetivos da regulação são basicamente: incentivar investimentos e suportar eficiência na produção e no uso (LEVY; SPILLER, 1993; KESSLER, 2011). Os objetivos da regulação são: buscar eficiência econômica de maneira a garantir o serviço de menor custo para o usuário; evitar abusos de poder no monopólio, garantindo a menor diferença entre preço e custo, de forma equivalente aos níveis desejados de qualidade do serviço; assegurar o serviço universal; assegurar a qualidade do serviço ofertado; estabelecer canais para atender a reclamações dos usuários a respeito da prestação dos serviços; promover a inovação; assegurar a padronização tecnológica e a compatibilidade dentre equipamentos; e proteger o meio ambiente (PIRES; PICCININI, 1999).

Nesta perspectiva, a economia da regulação sustenta a operação de restrições governamentais sobre as decisões em alguns setores de infraestrutura no país a respeito do preço e quantidade (BORGES; BORGES, 2014). A justificativa para a intervenção governamental é que em determinadas condições a concorrência não funciona muito bem, seja pela existência de um monopólio natural, seja pela existência de externalidades (MAFRA, 2010; BORGES; BORGES, 2014).

As agências reguladoras e as normas regulatórias surgiram diante do imperativo de regular as atividades que antes eram do setor público e tornaram-se responsabilidade da área privada. $\mathrm{A}$ Agência Nacional de Energia Elétrica - Aneel, por meio da sua regulamentação, vem buscando resultados e melhorando o seu desempenho institucional sob a ótica da sustentabilidade verificado a partir do referencial normativo de desenvolvimento sustentável (BORGES; BORGES, 2014).

Nestas perspectivas, o órgão regulador do setor elétrico, a Aneel, vem incentivando as concessionárias a terem uma matriz energética mais sustentável, apoiando projetos de pesquisa de desenvolvimento e eficiência energética, viabilização inovações promovendo um crescimento significativo na melhoria de seus processos e serviços, enfrentando os desafios do setor de energia elétrica, seja promovendo o uso eficiente e racional da energia elétrica ou associado às ações de combate ao desperdício. Aneel procura incentivar e promover a inovação, fomentando a cultura, estimulando diversas pesquisas para fomentar o desenvolvimento do setor elétrico, melhorando a prestação de serviços e provendo a segurança do fornecimento de energia elétrica no país.

Estudos desenvolvidos por Borges e Borges (2014), objetivaram a apuração e análise dos resultados do desempenho institucional da sustentabilidade da Agência Nacional de Energia Elétrica, a partir dos indicadores apurados. $\mathrm{Na}$ investigação destes autores, verificou-se que a agência se encontra qualificada em seu desempenho institucional quanto à sustentabilidade e apresenta avanços graduais e constantes de aproximação entre suas informações e a sociedade brasileira na medida em que tem ampliado seus canais de acesso à população.

Os avanços graduais em direção à sustentabilidade foram alcançados em virtude da notada contribuição dos seguintes indicadores: ratificação de acordos globais, gastos com pesquisa 


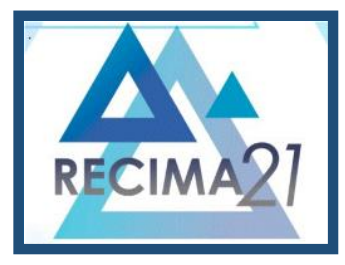

\section{RECIMA21 - REVISTA CIENTÍFICA MULTIDISCIPLINAR}

ESTRUTURA INSTITUCIONAL DO SETOR DE ENERGIA ELÉTRICA NO BRASIL E O DESENVOLVIMENTO SUSTENTÁVEL e desenvolvimento, acesso aos serviços de telefonia, e acesso à internet. Porém, o estudo adverte que existem limitações no ambiente da sustentabilidade institucional, especialmente nos indicadores: gastos públicos com a proteção ao meio ambiente e existência de conselhos municipais. Estas limitações tendem a ser reduzidas com a descentralização efetiva das atividades de regulação e com o uso de indicadores, apurados sistematicamente, como subsídio contribuinte ao processo decisório na agência.

\section{CONSIDERAÇÕES FINAIS}

Diante do desafio deste artigo que é de analisar, no campo teórico, as relações entre sustentabilidade energética e a Teoria da regulação de maneira a contribuir ao aperfeiçoamento do processo decisório no setor elétrico Brasileiro, a investigação inferi que apenas por meio da construção de um modelo de indicadores de sustentabilidade haverá orientação estratégica ao processo decisório em instituições reguladoras de eletricidade.

É importante destacar que os desafios do setor elétrico brasileiro residem no atendimento premente por eletricidade e na necessidade de operar mecanismos eficientes para lidar com as questões ambientais. Todavia, não podem ser desenvolvidos planos de gestão, iniciativas de auditorias ou mecanismos de controle interno que procurem abordar os desafios mencionados se não existirem indicativos de sustentabilidade apurados junto a cada instituição componente do setor elétrico. A aplicação e a análise de indicadores de sustentabilidade nas instituições do setor elétrico também poderão servir de orientação na busca de caminhos estratégicos, inclusive, que levem a uma matriz elétrica sustentável.

O estudo ainda tem consciência da impossibilidade em promover a melhoria concreta do padrão de vida da população paraense exclusivamente a partir da energia elétrica. E nesta perspectiva também evidencia a necessidade de prosseguir as investigações a partir de outros setores estratégicos ao processo de desenvolvimento socioeconômico, como os setores de transporte e telecomunicações.

Esta investigação sugestiona a possibilidade de novas pesquisas voltadas às outras organizações do setor elétrico do país que não foram objeto de estudo nesta ocasião, assim como, da fomentação de sistemas que garantam a periodicidade na mensuração dos indicadores. $O$ propósito é o de estender as condições de exame da sustentabilidade no aspecto institucional do setor de energia elétrica do país e auxiliar a tomada de decisão com base nos resultados destes indicadores apurados. 


\section{RECIMA21 - REVISTA CIENTÍFICA MULTIDISCIPLINAR}

ESTRUTURA INSTITUCIONAL DO SETOR DE ENERGIA ELÉTRICA NO BRASIL E O DESENVOLVIMENTO SUSTENTÁVEL

\section{REFERÊNCIAS}

ABBASI, T.; TAUSEEF, S. M.; ABBASI, S. A. Biogas Energy. Switzerland: Springer Science \& Business Media, 2011.

BORGES, F. Q. Indicadores de sustentabilidade para a Energia elétrica no estado do Pará. Revista Brasileira de Energia, v. 15, n. 2, p. 119-151. 2009.

BORGES, F. Q.; RODRIGUES, I. M.; OLIVEIRA, A. S. P. Paradoxo da energia elétrica no estado do Pará: um estudo dos fatores que contribuem às altas tarifas residenciais (2005-2014). Observatorio de la Economía Latinoamericana. Servicios Académicos Intercontinentales, n. 231, May., 2017.

BORGES, F. Q.; CHOTOE, R. Análise econômica da variação de custos da fonte solar para a geração de energia elétrica no Brasil (2000-2012). Observatório de la economía latinoamericana. n. 190, 2013.

BORGES, F. Q.; BORGES, F. Q. Desempenho institucional e a gestão da sustentabilidade: uma análise de indicadores na Aneel. Revista Economia \& Gestão, v. 14, n. 35, abr./jun. 2014.

BORGES, F. Q. Sustentabilidade institucional no setor elétrico brasileiro. Revista Pretexto. v. 16, n.1, jan./mar. 2015.

BURSZTYN, M. Estado e meio ambiente no Brasil. In.: Para pensar o desenvolvimento sustentável. São Paulo: Brasiliense, 1998. p. 83-101.

CAMARGO, A. S. G.; UGAYA, C. M. L.; AGUDELO, L. P. P. Proposta de definição de indicadores de sustentabilidade para geração de energia elétrica. Revista Educação e Tecnologia, Rio de Janeiro, v. 8, 2004.

FURTADO, C. Capitalismo Global. São Paulo: Paz e Terra, 2007.

GARCÍA, H. C. L. Modelo regulatório do setor elétrico no Brasil e sua repercussão jurídica nos contratos de concessão de transmissão de energia elétrica. 2010. Dissertação (Mestrado) Programa de Engenharia Elétrica, Universidade de São Paulo-USP, 2010.

GLAVIC, P.; LUKMAN, R. Review of sustainability terms and their definitions. Journal of Cleaner Production, v. 15, p.1875-1885, 2007.

HAMMOND, A. et al. Environmental Indicators: a systematic approach to measuring and reporting on environmental policy performance in the context of sustainable development. Washington: WRI, 1995.

INSTITUTO BRASILEIRO DE GEOGRAFIA E ESTATÍSTICA (IBGE). Indicadores de desenvolvimento sustentável do Brasil. Disponível em: www.ibge.gov.br. Acesso em: 16 mar. 2020.

KESSLER, D. P. Regulation versus litigation: perspectives from economics. London: National Bureau of economic Research, 2011.

LEVY, B.; SPILLER, P. T. Regulations, institutions and commitment in telecommunications: a comparative analysis of five country studies. In: BRUNO, M. (Org.). Proceedings of the World Bank annual conference on development economics. Califórnia: World Bank, 1993.

MAFRA, D. D. Análise da composição tarifária de energia elétrica em Santa Catarina. 2010. (Monografia) - Universidade Federal de Santa Catarina-UFSC, Florianópolis, 2010. 


\section{RECIMA21 - REVISTA CIENTÍFICA MULTIDISCIPLINAR}

ESTRUTURA INSTITUCIONAL DO SETOR DE ENERGIA ELÉTRICA NO BRASIL E O DESENVOLVIMENTO SUSTENTÁVEL

MARZALL, K. Indicadores de sustentabilidade para agroecossistemas.1990. Dissertação (Mestrado) - Universidade Federal do Rio Grande do Sul, Porto Alegre, 1999.

OWUSU, P.; ASUMADU-SARKODIE, S. A review of renewable energy sources, sustainability issues and climate change mitigation. Cogent Engineering, v. 3, n. 1, 2016.

PIRES, J. C. L.; PICCININI, M. A regulação dos setores de infraestrutura no Brasil. In: Giambiagi, F. \& Moreira, M. (Orgs.) A economia brasileira nos anos 90. Rio de Janeiro: BNDES, 1999.

REIS, Lineu Belico dos; FADIGAS, Eliane Aparecida Faria Amaral; CARVALHO, Cláudio Elias. Energia, recursos naturais e a prática do desenvolvimento sustentável. Barueri: Manole, 2012. p. 120.

TÁRREGA, M. C. V.; PEREZ, H. L. A. A tutela jurídica da biodiversidade: a influência da convenção sobre a diversidade biológica no sistema internacional de patentes. In: TÁRREGA, M. C. V. (Coord.). Direito ambiental e desenvolvimento sustentável. São Paulo: RCS Editora, 2007. p. 29-30.

VAN MARREWIJK, M.; HARDJONO, T. W. European corporate sustainability framework for managing complexity and corporate transformation. Journal of Business Ethics, v. 44, n. 2, May 2003. 